\title{
Emission characteristics of odor from salted food materials using Spam
}

\author{
Min-Hee Lee, Ki-Hyun Kim ${ }^{\star}$, Yong-Hyun Kim and Sang-Hee Jo \\ Dept. of Earth \& Environmental Sciences, Sejong University \\ (Received September 14, 2012; Revised October 19, 2012; Accepted October 30, 2012)

\section{염처리 음식물의 냄새성분 배출특성에 대한 연구: 스팸을 중심으로 \\ 이민희 · 김기현 $\cdot$ 김용현 · 조상희 \\ 세종대학교 환경에너지융합학과} \\ (2012. 9. 14. 접수, 2012. 10. 19. 수정, 2012. 10. 30. 승인)
}

\begin{abstract}
In this study, the emission characteristics of volatile and odorant species released from salted meat product (Spam) was investigated as a function of time. Gas samples released from Spam samples were analyzed for volatile organic compounds (VOC) and sulfur compounds (RSC) at five different times for the elapsed (E) days of $0,1,3,6$, and 9 (E-0 to E-9) by GC/MS and GC/PFPD system, respectively. Results indicated that reduced sulfur, aldehyde, and ketone groups were the dominant odorants. Especially, hydrogen sulfide was the predominant in concentration and odor activity value (OAV) during the fresh stage. Its concentration was $1465 \mu \mathrm{g} / \mathrm{m}^{3}$ (60.0\% of the total mass) in E-0 and $455 \mu \mathrm{g} / \mathrm{m}^{3}$ (28.0\%) in E-1, while its OAV was 19.4 (78.3\%: E-0) and 6.02 (41.7\%: E-1). On the other hand, the concentration of acetone showed the maximum values in the decaying stage (E-3: 451 (43.2\%), E-6: 369 (64.2\%), and E-9: $1150 \mu \mathrm{g} / \mathrm{m}^{3}(70.2 \%)$ ). Furthermore, the concentration of 2,3-butanedione was also detected considerably from decaying sample (E-3: $17.6(1.68 \%)$, E6: $16.1(2.80 \%)$, and E-9: $179 \mu \mathrm{g} / \mathrm{m}^{3}(10.9 \%)$ ). However, OAV of acetone was insignificant $(<0.01 \%)$ in the decaying stage, while that of 2,3-butanedione was relatively high in the range of 1.14-11.6 (14.5-76.2\% of $\Sigma \mathrm{OAV})$. It thus confirmed that the major odorant groups generated from Spam samples changed with the progress of decay such as sulfur (fresh stage), aldehyde (intermediate stage), and ketone compounds (decaying stage).

요 약: 본 연구에서는 염처리 음식물의 냄새성분 배출특성을 파악하고자 스팸을 조사대상으로 선정하 여 시간경과에 따른 휘발성화학물질의 발생특성을 파악하고자 하였다. 이를 위하여 총 9 일 동안 5 회에 걸쳐 시료를 채취 후 GC/MS 시스템과 GC/PFPD 시스템을 이용하여 분석하였다. 분석 결과 연구기간 동 안 환원황, 알데하이드, 케톤류의 냄새성분들이 주로 발생하는 것으로 나타났다. 신선기에 해당하는 E-0, E-1일은 hydrogen sulfide의 농도가 각각 $1465 \mu \mathrm{g} / \mathrm{m}^{3}(60.0 \%), 455 \mu \mathrm{g} / \mathrm{m}^{3}(28.0 \%)$ 로 가장 높게 나타났다. $\mathrm{OAV}$ (악취활성값) 또한 E-0 일은 19.4 (78.3\%), E-1 일은 6.02 (41.7\%)로 가장 높게 나타났다. 부패기에 해당하는 E-3, E-6, E-9일에는 ketone류의 acetone이 각각 451 (43.2\%), $369(64.2 \%), 1150 \mu \mathrm{g} / \mathrm{m}^{3}$ (70.2\%)
\end{abstract}

$\star$ Corresponding author

Phone : +82-(0)2-499-9151 Fax : +82-(0)2-3408-4320

E-mail : khkim@sejong.ac.kr 
로 나타났다. 그 뒤를 이어 2,3-butanedione이 각각 $17.6(1.68 \%), 16.1(2.80 \%), 179 \mu \mathrm{g} / \mathrm{m}^{3}(10.9 \%)$ 로 나 타났다. 이들 성분의 실질적인 냄새 기여도를 $\mathrm{OAV}$ 로 비교하면, acetone은 $0.001(0.01 \%)$ 이하로 미미한 수준이지만, 2,3-butanedione은 1.14-11.6 (14.5-76.2\%)으로 높게 나타났다. 본 연구의 결과, 신선기에는 환 원황 그룹, 신선기와 부패기의 중간 시점에는 알데하이드 그룹, 부패기에는 케톤 그룹 성분들이 가장 중 요한 냄새 요인으로 작용하는 것을 확인하였다.

Key words: spam, emission characteristic, emission compounds, odor threshold

\section{1. 서 론}

햄류는 식육의 육괴에 다른 식품 또는 식품첨가물 을 첨가한 후 숙성 - 건조하거나 훈연 또는 가열처리하 여 가공한 것으로 ${ }^{1}$ 사람들이 즐겨찾는 식품에 속한다. 캔으로 제조하여 판매하는 햄류의 판매량은 꾸준한 상승세 (2010 년 대비 2011 년 약 13\% 증가)를 나타 내고 있다. ${ }^{2}$ 이러한 식품류는 유통 및 보존을 위해 식 품첨가물과 육괴를 혼합하여 제조함으로써, 특유의 냄 새가 발생한다. 이러한 냄새는 시간의 경과에 따라 그 강도 및 조성에 변화가 나타난다. 이와 같이 햄류에서 발생하는 휘발성물질의 발생특성을 정의하는 것은 중 요한 의미를 지닌다.

휘발성유기화합물(volatile organic compounds, VOC) 의 분석을 위해 보편적으로 가스크로마토그래프(gas chromatograph: $\mathrm{GC}$ )와 불꽃이온화검출기(flame ionization detector: FID) 또는 질량분석기(mass spectrometer: $\mathrm{MS}$ )를 연계한 시스템을 사용하고 있다. ${ }^{3}$ 조사대상물 질의 유형이 황성분의 함유도가 높은 성분들이 주를 이룰 경우, $\mathrm{GC} / \mathrm{FID}$ 나 $\mathrm{GC} / \mathrm{MS}$ 외에도 추가적으로 펄스 형 불꽃광도 검출기(pulsed flame photometric detector: PFPD)를 연계한 시스템을 사용하고 있다..$^{4-6}$ 이러한 기기 중심의 분석법 외에도 인간의 후각을 이용하는 olfactometry와 같은 감지기법 등도 사용하고 있다. Olfactometry 기법은 기기분석과 동시에 진행할 경우, 분석대상 시료의 휘발성물질에 대한 정량자료와 함께 냄새의 강도나 특성을 파악하는데 유용한 정보를 제 시할 수 있다. ${ }^{7-9}$

본 연구에서는 시중에서 쉽게 구매가 가능한 햄류 에 해당하는 스팸을 검체로 선정하여 시간의 경과에 따른 냄새물질의 발생특성을 $\mathrm{VOC}$ 중심으로 분석하고 자 하였다. 이러한 분석결과들을 토대로 휘발성물질의 배출 특성을 시간의 경과에 따라 경향성을 정의하고 파악하고자 하였다. 이를 통해 음식물로부터 발생하는 냄새물질의 배출특성을 신선기와 부패기로 구분하여
정의하고자 하였다.

\section{2. 실 험}

\section{1. 시약 및 재료}

VOC 표준 시약인 isobutyl alcohol (i-BuAl), acetaldehyde (AA), propionaldehye (PA), butyraldehye (BA), isovaleraldehye (IA), n-valeraldehyde (VA), methyl ethyl ketone (MEK), methyl isobutyl ketone (MIBK), n-butyl acetate $(\mathrm{BuAc})$, benzene $(\mathrm{B})$, toluene $(\mathrm{T})$, styrene $(\mathrm{S})$, $p$-xylene ( $\mathrm{p}$-X), $m$-xylene $\mathrm{m}$-X), $o$-xylene (o-X), propionic acid (PPA), butyric acid (BTA), isovaleric acid (IVA), n-valeric acid (VLA)는 Sigma Aldrich (USA)사의 특 급 시약을 구매하여 사용하였다. Sulfur 그룹의 6 가 지 성분인 hydogen sulfide $\left(\mathrm{H}_{2} \mathrm{~S}\right)$, sulfur dioxide $\left(\mathrm{SO}_{2}\right)$, methanethiol $\left(\mathrm{CH}_{3} \mathrm{SH}\right)$, dimethylsulfide (DMS), carbon di sulfide $\left(\mathrm{CS}_{2}\right)$, dimethyldisulfide (DMDS)는 $30 \mathrm{ppm}$ 수준 의 원표준시료(primary standerd: PS, Rigas, Korea)를 구매하여 사용하였다.

검체로 사용한 스팸은, 시중에서 일반적으로 판매중 인 제품(SPAM classic, CJ 제일제당(주) 을 구매하여, 연구실에서 주요 냄새성분들을 위주로 분석하였다.

\section{2. 표준 시료 조제}

총 19 가지의 $\mathrm{VOC}$ 성분(i-BuAl, AA, PA, BA, IA, VA, MEK, MIBK, BuAc, B, T, S, p-X, m-X, o-X, PPA, BTA, IVA, VLA)들을 포함하는 액상표준시료를 조제하여 검량에 활용하였다. VOC 성분(19 종)의 경 우, 액상 표준시료(B 성분 기준: $1.22,6.12,12.2$, $24.5,61.2 \mathrm{ng} / \mu \mathrm{L})$ 로 5 점 검량을 실시하였다. 준비한 $\mathrm{VOC}$ 의 액상 표준시료는 고체흡착관에 직접 주입하는 방식으로 검량하였다. 액상 표준시료는 고순도 질소 (high purity nitrogen $>99.999 \%$ )로 flushing 을 하는 상 태에서 주사기로 silicon tubing을 관통하여 튜브의 흡 착제에 직접 주입하였다. 이때 $\mathrm{N}_{2}$ 가스는 $50 \mathrm{~mL}$ 분으 

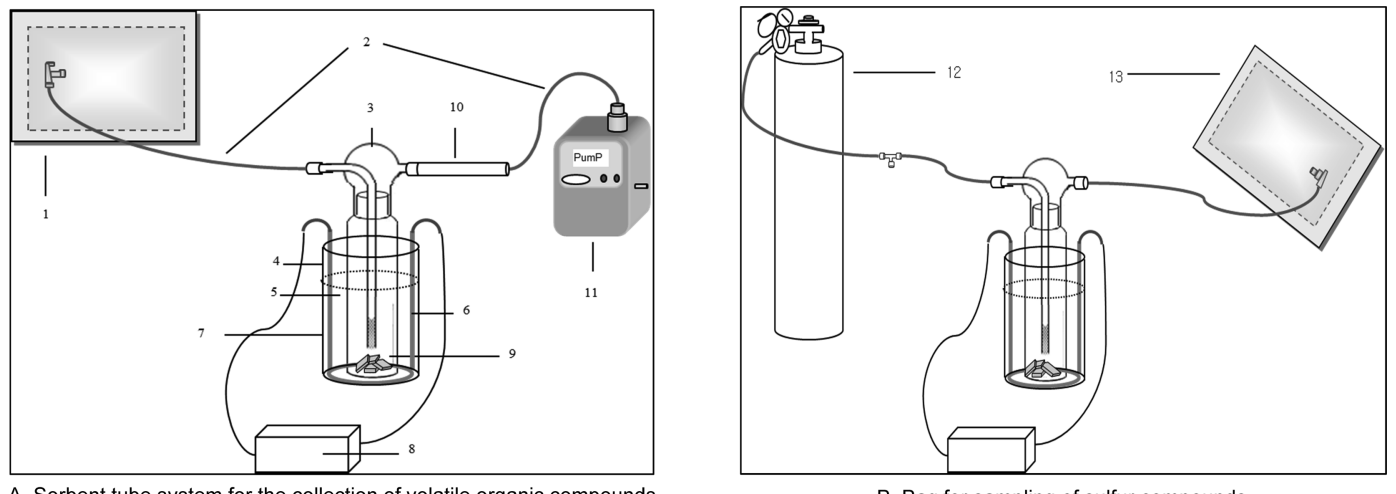

B. Bag for sampling of sulfur compounds
ig. 1. Schematic of sampling apparatus for VOCs and sulfur gases emitted from SPAM samples through time Labels: $1.10 \mathrm{~L}$ polyester aluminum bag filled with pure $\mathrm{N}_{2} ; 2$. Silicon tubing; 3. Impinger bottle; 4 . Aluminum container; 5. Water heated to $2{ }^{\circ} \mathrm{C} ; 6$. Heater; 7. Sensor; 8. Temperature regulator; 9. SPAM; 10. Sorbent tube; 11 . Mini vacuum pump; 12. Pure air gas cylinder; and 13. $10 \mathrm{~L}$ PEA bag filled with pure $(99.999 \%) \mathrm{N}_{2}$

로 10 분간 지속적으로 튜브로 흘려주었다. 액상표준 시료를 이용한 검량은 실험을 진행한 첫날과 마지막 날에 걸쳐 실시하였다.

황계열 성분의 경우, 총 6 가지 성분 $\left(\mathrm{H}_{2} \mathrm{~S}, \mathrm{SO}_{2}\right.$, $\left.\mathrm{CH}_{3} \mathrm{SH}, \mathrm{DMS}, \mathrm{CS}_{2}, \mathrm{DMDS}\right)$ 을 포함하는 기체상 작업 용 표준시료(working standard: WS)를 준비하였다. 이 들의 검량을 위해 6 가지 sulfur 그룹의 성분들을 포 함한 $30 \mathrm{ppm}$ 수준의 원표준시료를 $\mathrm{N}_{2}$ 가스로 $10 \mathrm{~L}$ $\mathrm{PEA}$ bag에서 희석하여 $10 \mathrm{ppb}$ 의 가스상 작업용 표준 시료를 조제하였다.

\section{3. 시료 채취 및 전처리}

시료의 준비 및 채취는 다음과 같은 방식으로 진행 하였다. 스팸 약 $50 \mathrm{~g}$ (약 $1.5 \times 2.5 \times 1.5 \mathrm{~cm}, 7$ 조각)을 깨끗이 세척한 임핀저에 담아 물중탕 $\left(25{ }^{\circ} \mathrm{C}\right)$ 방식으로 실험기간 동안 보관하였다(Fig. 1). VOC 성분의 분석 을 위한 시료를 확보하기 위하여, 임핀저의 기체유입 부에 고순도 질소 가스를 가득 채운 $10 \mathrm{~L} \mathrm{PEA} \mathrm{bag}$ 을 연결하였다. 기체배출부에는 고체흡착관(3 bed sorbent tube: Tenax+Carbopack B+Carboxen)을 전단부에 연 결하였다. 고체흡착관의 후단부에는 Mass Flow Controller (MFC)를 장착한 펌프(SIBATA MP- 530 )를 연결하여 $50 \mathrm{~mL} /$ 분의 유속으로 총 $500 \mathrm{~mL}$ 의 시료를 채취 하였다. 황화합물의 경우 임핀저의 기체유입부에 $10 \mathrm{~L}$ 의 고순도 공기(high purity air: 99.999\%)를 장착 후, $100 \mathrm{~mL}$ 분의 유속으로 임핀저 내부로 주입하였다. 이때, 성분에 따라 파괴 범위를 감안하여, 시료의 채 취량을 조절함으로써 검량선 범위 내에서 분석결과를
도출하였다. 시료의 채취를 마치면, 다음 시점의 시료 를 채취할 때까지 임핀저의 유입부와 배출부를 개방 하여 자연적으로 시료의 부패가 진행할 수 있도록 하 였다. 시간의 경과에 따른 냄새물질들의 발생특성을 음식물의 신선한 상태와 부패한 상태에 걸쳐 포괄적 으로 분석하기 위하여, 시간의 경과에 따른 냄새물질 들의 발생 특성을 신선한 시점과 부패한 시점으로 구 분하였다. 이를 위하여 최초 시료채취를 기점으로 총 9 일 동안 5 회 $(0,1,3,6,9$ 일 $)$ 에 걸쳐 시료를 채취 하고 분석을 진행하였다(Table 1A). Sample code는 경 과 기간(elapsed day)에 따라 각각 E-0, E-1, E-3, E-6, E-9로 하였다.

\subsection{Quality assurance/quality control (QA/QC)}

스팸에서 발생한 냄새성분들의 정량 및 분석시스템 에 대한 $\mathrm{QA} / \mathrm{QC}$ 를 실시하였다(Table 2). 19 종 $\mathrm{VOC}$ 성분의 경우, 5 점 검량을 적용하기 위해 5 개의 농도 (B 성분 기준: $1.22,6.12,12.2,24.5,61.2 \mathrm{ng}$ )대로 준 비한 액상표준시료 $(1 \mu \mathrm{L})$ 를 준비하고 이를 튜브에 주 입하여, $\mathrm{GC} / \mathrm{MS} / \mathrm{TD}$ 시스템으로 검량선을 도출하였다. Sulfur 성분의 경우 air server (AS)를 이용하여 $\mathrm{TD}$ 에 $50 \mathrm{~mL} /$ 분의 유속으로 가스상표준시료를 $1,2,3,5,10$ 분씩 주입하는 방식으로 5 점 검량 $\left(\mathrm{SO}_{2}\right.$ 기준: 1.33 , $2.66,3.98,6.64,13.3 \mathrm{ng})$ 을 실시하였다. 또한, 최소검 출한계(method detection limit: $\mathrm{MDL}$ )를 산출하기 위 해, 검출한계에 근접한 수준의 표준시료를 7 회 반복 측정하였다. 재현성을 평가하기 위해, 동일한 조건에 서 작업용 표준시료를 3 회 반복 측정하였다. 
Table 1. Information concerning the sample preparation and the operational conditions of instrumental system for the analysis of VOC and reduced sulfur gases

A. Experimental code of SPAM samples at each sampling interval

\begin{tabular}{ccc}
\hline \hline [1] Information of SPAM sample (Initial weight $=49.95 \mathrm{~g})$ & \\
\hline Order & Elapsed time (day) & Sample code \\
\hline 1 & 0 & E-0 \\
2 & 1 & E-1 \\
3 & 3 & E-3 \\
4 & 6 & E-6 \\
5 & 9 & E-9 \\
\hline
\end{tabular}

B. Operational conditions of TD/GC/MS system for VOC analysis

\begin{tabular}{|c|c|c|c|}
\hline \multicolumn{4}{|c|}{ [1] GC (SHIMADZU GC-2010, JAPAN), MS (SHIMADZU GCMS-QP2010, JAPAN) } \\
\hline \multicolumn{4}{|c|}{ Column: CP Wax (diameter: $0.25 \mathrm{~mm}$, length: $60 \mathrm{~m}$, and film thickness: $0.25 \mu \mathrm{m}$ ) } \\
\hline \multicolumn{2}{|c|}{ Oven setting } & \multicolumn{2}{|c|}{ Detector setting } \\
\hline Oven temp: & $35{ }^{\circ} \mathrm{C}(10 \mathrm{~min})$ & Ionization mode: & EI \\
\hline Oven rate: & $6{ }^{\circ} \mathrm{C} / \mathrm{min}$ & Filament : & $70 \mathrm{eV}$ \\
\hline Max oven temp: & $215^{\circ} \mathrm{C}(10 \mathrm{~min})$ & Ion source temp.: & $200{ }^{\circ} \mathrm{C}$ \\
\hline Total time: & $50 \min$ & Interface temp.: & $200{ }^{\circ} \mathrm{C}$ \\
\hline Carrier gas: & He $(99.999 \%)$ & TIC scan range: & $35 \sim 260 \mathrm{~m} / \mathrm{z}$ \\
\hline Carrier gas flow: & $1 \mathrm{~mL} / \mathrm{min}$ & Threshold: & 100 \\
\hline \multicolumn{4}{|c|}{ [2] Thermal desorber (Unity, Markes, UK) } \\
\hline Cold trap sorbent: & \multicolumn{3}{|c|}{ Carbopack C + Carbopack B (volume ratio $=1: 1$ ) } \\
\hline Split ratio: & $1: 5$ & Adsorption temp.: & $-10^{\circ} \mathrm{C}$ \\
\hline Split flow: & $5 \mathrm{~mL} / \mathrm{min}$ & Desorption temp.: & $320^{\circ} \mathrm{C}$ \\
\hline Trap hold time: & $20 \mathrm{~min}$ & Flow path temp: & $150^{\circ} \mathrm{C}$ \\
\hline \multicolumn{4}{|l|}{ [3] Sorbent (Sampling) Tube } \\
\hline Sorbent material: & \multicolumn{3}{|c|}{ Tenax TA + Carbopack B + Carboxen $1000($ mass $(g)=100: 100: 100)$} \\
\hline Actual Loading Vol. & $500 \mathrm{~mL}$ & Desorption time: & $5 \mathrm{~min}$ \\
\hline Desorption flow: & $50 \mathrm{~mL} / \mathrm{min}$ & Desorption temp.: & $300{ }^{\circ} \mathrm{C}$ \\
\hline
\end{tabular}

\section{5. 미지성분들의 정량}

시간의 경과에 따라 스팸에서 방출하는 $\mathrm{VOC}$ 는 우 선 19 종의 표준시료를 이용하여 외부검량 (external calibration)을 실시하였다. 그리고 표준시료를 확보할 수 없는 성분들의 경우, 표준시료의 성분들에 대한 화 합물들의 감응계수 (response factor)와 탄소수의 관계 로부터 측정한 감응계수를 이용하여 농도를 측정하였 다. ${ }^{10}$ 이러한 추정을 위하여, 본 연구에서 선정한 19 가지의 $\mathrm{VOC}$ 성분들을 3 그룹의 화학종(그룹 1 (7 종): aldehyde 5 종 및 ketone 2 종; 그룹 2(8 종): aromatics 6 종, alcohol 1 종 및 ester 1 종; 그룹 3(4 종): fatty acid 4 종)으로 구분하여, 각 그룹별로 확보한 추정식 을 이용하여 첫날과 마지막날 확보한 19 종 성분들의 $\mathrm{RF}$ (response factor)값의 평균치를 적용하여 개별 성 분의 RF값을 유추하였다.

\section{6. 기기 및 분석 조건}

시간의 경과에 따라 신선기와 부패기에 스팸으로부 터 발생하는 냄새성분들의 특성을 평가하기 위해 $\mathrm{VOC}$ 와 sulfur 성분 분석 전용 시스템을 각각 이용하 여 분석하였다(Table 1B, 1C).

$\mathrm{VOC}$ 성분의 분석은 GC/MS [(Shimadzu GC-2010, Japan)/(Shimadzu GCMS -QP2010, Japan)]와 저온농 축열탈착시스템(TD, Unity, Markes International, Ltd, $\mathrm{UK}$ )를 활용하였다. 이때 VOC 성분의 분리를 위해, CP-Wax (diameter: $0.25 \mathrm{~mm}$, length: $60 \mathrm{~m}$, film thickness: $0.25 \mu \mathrm{m})$ 을 이용하였다. 매 시점별로 확보한 시료는 $\mathrm{GC} / \mathrm{MS}$ 시스템의 성분별 분석 주기를 매회 50 분으로 설정하여 분석하였다.

Sulfur 성분은 GC/PFPD [(CP-3800, Varian, USA)/ (pulsed flame photometric detector, Varian, USA)]를 
Table 1. Continued

C. Operational conditions of TD/GC/PFPD system for RSC analysis

\begin{tabular}{|c|c|c|c|c|c|c|}
\hline \multicolumn{7}{|c|}{ [1] GC (CP-3800, Varian, CA, USA) } \\
\hline \multicolumn{7}{|c|}{ Column: BP-1, SGE (Australia, diameter: $0.32 \mathrm{~mm}$, length: $60 \mathrm{~m}$, and film thickness: $5 \mu \mathrm{m}$ ) } \\
\hline \multicolumn{3}{|c|}{ Oven setting } & \multicolumn{4}{|c|}{ PFPD detector } \\
\hline Initial temp: & & $80{ }^{\circ} \mathrm{C}$ & \multicolumn{2}{|c|}{ Detector temp: } & & $200{ }^{\circ} \mathrm{C}$ \\
\hline Rate: & & $8^{\circ} \mathrm{C} / \mathrm{min}$ & \multicolumn{2}{|c|}{ Air(1) flow: } & & $17 \mathrm{~mL} / \mathrm{min}$ \\
\hline Final temp: & & $200{ }^{\circ} \mathrm{C}$ & \multicolumn{2}{|c|}{ Air(2) flow: } & & $10 \mathrm{~mL} / \mathrm{min}$ \\
\hline Initial hold: & & $5 \min$ & \multicolumn{2}{|c|}{$\mathrm{H}_{2}$ flow: } & & $14 \mathrm{~mL} / \mathrm{min}$ \\
\hline Final hold: & & $5 \min$ & & & & \\
\hline Total time: & & $25 \mathrm{~min}$ & & & & \\
\hline \multicolumn{7}{|c|}{ [2] Combined application of air server (AS) and thermal desorber (TD) $)^{\mathrm{a}}$} \\
\hline Cold trap: & \multicolumn{5}{|c|}{ Carbopack B + Silica Gel $=1.5: 2.5$ (Volume ratio) } & \multirow[b]{2}{*}{$-15{ }^{\circ} \mathrm{C}$} \\
\hline Split ratio: & & $1: 10$ & \multirow{2}{*}{\multicolumn{2}{|c|}{$\begin{array}{l}\text { Trap low: } \\
\text { Trap high: }\end{array}$}} & & \\
\hline Split flow: & & $15 \mathrm{~mL} / \mathrm{min}$ & & & & $250{ }^{\circ} \mathrm{C}$ \\
\hline Hold time: & & $5 \mathrm{~min}$ & \multicolumn{2}{|c|}{ Flow path temp: } & & $80{ }^{\circ} \mathrm{C}$ \\
\hline \multicolumn{7}{|c|}{ [3] Sampling information of air server (AS) } \\
\hline Sample & \multicolumn{6}{|c|}{ Compound } \\
\hline code & $\mathrm{H}_{2} \mathrm{~S}$ & $\mathrm{SO}_{2}$ & $\mathrm{CH}_{3} \mathrm{SH}$ & DMS & $\mathrm{CS}_{2}$ & DMDS \\
\hline \multicolumn{7}{|c|}{ Sampling volume $(\mathrm{mL})^{\mathrm{b})}$} \\
\hline $\mathrm{E}-0$ & $5^{c)}$ & 250 & 50 & 250 & 250 & 250 \\
\hline E-1 & 20 & 250 & 20 & 250 & 250 & 250 \\
\hline E-3 & 50 & 250 & 250 & 250 & 250 & 250 \\
\hline E-6 & 500 & 500 & 500 & 500 & 500 & 500 \\
\hline E-9 & 500 & 500 & 500 & 500 & 500 & 500 \\
\hline
\end{tabular}

a)TD (UNITY, Markes International, Ltd., UK)

b) TD operation flow rate: $50 \mathrm{~mL} / \mathrm{min}$

c) The back-up nitrogen gas supplied at a flow rate of $50 \mathrm{~mL} / \mathrm{min}$ for 1 minute duration during injection of samples

$\mathrm{GC} / \mathrm{MS}$ 와 마찬가지로 저온농축열탈착시스템에 연계 하여 분석 하였다. $\mathrm{TD}$ 에 대한 시료의 주입조건은 Table 1 C에 제시한 바와같이 air server (AS)를 이용하 여 설정하였다. 분석 컬럼은 $\mathrm{BP}-1$, SGE(diameter $0.32 \mathrm{~mm}$, length $60 \mathrm{~m}$, and film thickness $5 \mu \mathrm{m}$, Australia)을 이용하였다. Sulfur 성분의 정량 분석을 위해 매회 25 분 주기로 분석하였다.

\section{3. 결과 및 토의}

\section{1. 분석 시스템의 $\mathrm{QA} / \mathrm{QC}$}

본 연구에서는 냄새성분들의 농도를 정량적으로 분 석하기 위하여, 액상으로 준비한 VOC 표준시료와 가 스상으로 준비한 sulfur 성분의 표준시료를 이용하여 정량 및 분석시스템에 대한 $\mathrm{QA} / \mathrm{QC}$ 를 실시하였다 (Table 2). 검량선의 $\mathrm{R}^{2}$ 값은(아세트알데하이드 성분을 제외한) 18 가지 성분에서 두번 모두 0.99 이상의 직
선성을 보였다. 최소검출한계(method detection limit: $\mathrm{MDL}$ )는 표준시료를 7 회 반복 측정한 결과(편차)에 3.14 (7회 반복분석에 대한 $99 \%$ 신뢰구간에서의 t값)를 곱하여 계산하였다. Table 2에 제시한 검출한계에 대 한 표기는 절대질량 $(\mathrm{ng})$ 뿐만이 아닌 시료채취의 부 피 $(500 \mathrm{~mL})$ 를 감안하여, 질량/부피 $\left(\mu \mathrm{g} / \mathrm{m}^{3}\right)$ 로 환산하였 다. 그리고 이를 SI 규격에 맞추어 $\mathrm{nmol} / \mathrm{mol}(\mathrm{ppb})$ 로 제시하였다. 그러나 본 연구의 결과를 해석하는 단계 에서 각 물질들의 농도를 합하여 제시하는 부분을 감 안하여, 본 연구의 결과는 기본적으로 질량/부피 $(\mu \mathrm{g} /$ $\mathrm{m}^{3}$ )를 기준으로 사용하였다. 그 결과, 각 성분별로 $\mathrm{MDL}$ 은 0.01-1.67 ng으로 나타났다. 재현성을 평가하 기 위해, 동일한 조건에서 작업용 표준시료를 3 회 반 복 측정하여 성분별 상대표준오차(relative standard error: RSE)를 산출하였다. 그 결과 $\mathrm{VOC}$ 성분의 RSE 값은 모두 $5 \%$ 이내를 유지하였다.

Sulfur 성분의 경우 $\mathrm{R}^{2}$ 값은 모두 0.99 이상을 보였 
Table 2. Calibration and QA parameters for VOC and sulfur gases from Spam sample A. VOC

\begin{tabular}{|c|c|c|c|c|c|c|c|c|c|c|c|c|c|}
\hline \multirow[b]{2}{*}{ Order } & \multirow[b]{2}{*}{ Group } & \multicolumn{2}{|l|}{ Compound } & \multicolumn{3}{|c|}{$\mathrm{RF}^{\text {a) }}$} & \multicolumn{3}{|c|}{$\mathrm{R}^{2}$} & \multicolumn{3}{|c|}{ MDL } & \multirow{2}{*}{$\begin{array}{l}\text { RSE } \\
(\%)^{\text {b) }}\end{array}$} \\
\hline & & full name & $\begin{array}{l}\text { short } \\
\text { name }\end{array}$ & $\begin{array}{l}\operatorname{Exp}_{-} \\
\text {day } 0\end{array}$ & $\begin{array}{l}\operatorname{Exp}_{-} \\
\text {day } 9\end{array}$ & Mean & $\begin{array}{l}\operatorname{Exp}_{-} \\
\text {day } 0\end{array}$ & $\begin{array}{c}\text { Exp_da } \\
\text { y } 9\end{array}$ & Mean & (ng) & $\left(\mu \mathrm{g} / \mathrm{m}^{3}\right)$ & $\begin{array}{c}(\mathrm{nmol} / \\
\mathrm{mol})\end{array}$ & \\
\hline 1 & Alcohol & Isobutyl alcohol & $\mathrm{i}-\mathrm{BuAl}$ & 93667 & 92778 & 93223 & 0.9969 & 0.9972 & 0.9971 & 0.02 & 0.04 & 0.014 & 1.73 \\
\hline 2 & \multirow{5}{*}{ Aldehyde } & Acetaldehyde & $\mathrm{AA}$ & 532 & 487 & 510 & 0.9619 & 0.9698 & 0.9659 & 1.67 & 3.35 & 1.858 & 2.52 \\
\hline 3 & & Propionaldehyde & PA & 12017 & 11950 & 11984 & 0.9991 & 0.9991 & 0.9991 & 0.16 & 0.33 & 0.139 & 3.49 \\
\hline 4 & & Butyraldehyde & BA & 43572 & 43467 & 43520 & 0.9963 & 0.9938 & 0.9951 & 0.05 & 0.09 & 0.022 & 1.05 \\
\hline 5 & & Isovaleraldehyde & IA & 66125 & 65836 & 65981 & 0.9962 & 0.9932 & 0.9947 & 0.03 & 0.06 & 0.013 & 1.93 \\
\hline 6 & & n-Valeraldehyde & VA & 59322 & 59804 & 59563 & 0.9973 & 0.9973 & 0.9973 & 0.03 & 0.07 & 0.015 & 1.35 \\
\hline 7 & \multirow{2}{*}{ Ketone } & Methyl ethyl ketone & MEK & 48980 & 48566 & 48773 & 0.9969 & 0.9987 & 0.9978 & 0.04 & 0.08 & 0.022 & 1.79 \\
\hline 8 & & Methyl isobutyl ketone & MIBK & 117383 & 117646 & 117515 & 0.9998 & 0.9985 & 0.9992 & 0.02 & 0.03 & 0.008 & 0.85 \\
\hline 9 & Ester & n-Butyl acetate & $\mathrm{BuAc}$ & 121114 & 117791 & 119453 & 0.9982 & 0.9973 & 0.9978 & 0.02 & 0.03 & 0.008 & 0.79 \\
\hline 10 & \multirow{6}{*}{ Aromatics } & Benzene & $\mathrm{B}$ & 131760 & 131280 & 131520 & 0.9909 & 0.9930 & 0.9920 & 0.02 & 0.03 & 0.010 & 2.06 \\
\hline 11 & & Toluene & $\mathrm{T}$ & 168602 & 165819 & 167211 & 0.9995 & 0.9995 & 0.9995 & 0.01 & 0.02 & 0.005 & 0.83 \\
\hline 12 & & Styrene & S & 188198 & 191709 & 189954 & 0.9995 & 0.9997 & 0.9996 & 0.01 & 0.02 & 0.005 & 1.32 \\
\hline 13 & & p-Xylene & $\mathrm{p}-\mathrm{X}$ & 188510 & 184038 & 186274 & 0.9997 & 0.9987 & 0.9992 & 0.01 & 0.02 & 0.006 & 0.49 \\
\hline 14 & & m-Xylene & $m-X$ & 197068 & 193888 & 195478 & 0.9992 & 0.9994 & 0.9993 & 0.01 & 0.02 & 0.005 & 0.56 \\
\hline 15 & & o-Xylene & o-X & 198376 & 194140 & 196258 & 0.9991 & 0.9991 & 0.9991 & 0.01 & 0.02 & 0.005 & 0.73 \\
\hline 16 & \multirow{4}{*}{ Acid } & Propionic acid & PPA & 24574 & 23963 & 24269 & 0.9977 & 0.9953 & 0.9965 & 0.08 & 0.16 & 0.039 & 1.68 \\
\hline 17 & & n-Butyric acid & BTA & 71259 & 67832 & 69546 & 0.9963 & 0.9967 & 0.9965 & 0.03 & 0.06 & 0.014 & 0.13 \\
\hline 18 & & i-Valeric acid & IVA & 99441 & 94589 & 97015 & 0.9965 & 0.9935 & 0.9950 & 0.02 & 0.04 & 0.010 & 2.09 \\
\hline 19 & & n-Valeric acid & VLA & 79615 & 78949 & 79282 & 0.9918 & 0.9925 & 0.9922 & 0.02 & 0.05 & 0.012 & 0.97 \\
\hline
\end{tabular}

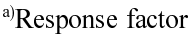

b) $1 \mu \mathrm{L}$ of $20 \mathrm{ng} / \mu \mathrm{L}$ (mean) liquid phase standard solution (4 th calibration standard) was injected 5 times to compute RSE (\%)

B. Sulfur

\begin{tabular}{|c|c|c|c|c|c|c|c|c|c|}
\hline \multirow{2}{*}{ Order } & \multirow{2}{*}{ Group } & \multicolumn{2}{|c|}{ Compound } & \multirow{2}{*}{$\mathrm{RF}$} & \multirow{2}{*}{$\mathrm{R}^{2}$} & \multicolumn{3}{|c|}{ MDL } & \multirow{2}{*}{$\begin{array}{l}\text { RSE } \\
(\%)^{\mathrm{c}}\end{array}$} \\
\hline & & Full name & Short name & & & (ng) & $\left(\mu \mathrm{g} / \mathrm{m}^{3}\right)$ & $(\mathrm{nmol} / \mathrm{mol})$ & \\
\hline 1 & \multirow{6}{*}{ Sulfur } & Hydrogen sulfide & $\mathrm{H}_{2} \mathrm{~S}$ & 191470 & 0.9901 & 0.02 & 0.04 & 0.027 & 2.36 \\
\hline 2 & & Sulfur dioxide & $\mathrm{SO}_{2}$ & 109968 & 0.9988 & 0.03 & 0.05 & 0.019 & 1.72 \\
\hline 3 & & Methyl sulfide & $\mathrm{CH}_{3} \mathrm{SH}$ & 147199 & 0.9902 & 0.02 & 0.04 & 0.022 & 1.34 \\
\hline 4 & & Dimethyl sulfide & DMS & 143627 & 0.9960 & 0.02 & 0.05 & 0.019 & 1.88 \\
\hline 5 & & Carbon sulfide & $\mathrm{CS}_{2}$ & 236758 & 0.9996 & 0.01 & 0.03 & 0.008 & 1.16 \\
\hline 6 & & Dimethyl disulfide & DMDS & 176986 & 0.9977 & 0.02 & 0.03 & 0.009 & 0.44 \\
\hline
\end{tabular}

${ }^{\text {c) }}$ Repetitive analyses $(\mathrm{n}=3)$ of sulfur gas standard $(10 \mathrm{ppb})$ : sample volume of $100 \mathrm{~mL}(\mathrm{FR}=50 \mathrm{~mL} / \mathrm{min})$

다. $\mathrm{MDL}$ 의 경우 0.01-0.03 $\mathrm{ng}$ 으로 나타났다. RSE값 은 모두 $5 \%$ 이내로 양호하게 나타났다. 참고로 악취 공정시험법상 $\mathrm{QC}$ 부분의 재현성은 relative standard deviation (RSD)값 $10 \%$ 또는 본 연구의 경우 $\mathrm{RSE}$ 기 준 $5 \%$ 범위 안에 들어가는 것을 권장하고 있다. ${ }^{11}$

\section{2. 시간경과에 따른 악취물질 발생 정도 및 패턴}

본 연구에서는 $\mathrm{GC} / \mathrm{MS}, \mathrm{GC} / \mathrm{PFPD}$ 를 이용한 기기분 석과 동시에 공기희석 관능법을 진행하였다. 따라서
공기희석 관능법을 토대로 시간의 경과에 따른 스팸 상태를 신선기(E-0과 E-1)와 부패기(E-3, E-6, E-9)를 부패기로 구분하였다. $\mathrm{VOC}$ 와 $\mathrm{RSC}$ 를 중심으로 냄새 물질의 발생특성과 그 경향성을 조사하고자 하였다.

공기희석 관능법은 악취를 유발하는 공기시료의 일 정량을 무취공기에 단계별로 희석시킴으로써, 인체가 감지하지 못하는 임계수준까지의 희석배수를 산출하 는 방법이다. 악취공정시험법을 기준으로 5 명의 판정 요원들이 제시한 각각의 희석배수에서 최대 - 최소값을 
제외한 나머지 값들의 기하평균으로 최종적인 희석배 수를 산출하였다. ${ }^{11}$ 그 결과 E-0과 E-1에서는 각각 2080, 669배, E-3, E-6, E-9에서는 173, 67, 45 배의 희석배수를 나타내었다. 본 연구에서는 시료에서 발생 하는 악취의 관능적인 특성을 “좋은 냄새”, “불쾌한 냄새" 등으로 판정요원들이 주관적으로 감지한 냄새 의 정보를 참고하여 평가를 진행하였다. 희석배수와 판정단의 주관적인 냄새정보를 취합하여 반영한 결과 E-0과 E-1에서의 희석배수는 더 높게 나타났지만 판 정단의 주관적인 판단에서 E-0과 E-1에서의 발생 냄 새는 향긋한 햄 냄새 즉, “좋은 냄새"라 평가하였다. 반면, E-3, E-6, E-9 에서는 앞서 채취한 시료보다 희 석배수는 떨어졌지만 곰팡이냄새 또는 역한 냄새 즉, “불쾌한 냄새”로 평가하였다.

$\mathrm{GC} / \mathrm{MS}, \mathrm{GC} / \mathrm{PFPD}$ 으로 분석한 냄새성분들의 해석 을 위해, 연구기간 동안 스팸으로부터 발생한 성분들 을 8 개의 화학종으로 구분하고, 냄새의 발생특성을 발생물질들의 농도크기와 발생빈도를 기준으로 구분 하여 제시하였다(Table 3). 농도의 산출 결과를 살펴보 면, sulfur 그룹의 경우 시간의 경과에 따라 $1613 \mu \mathrm{g} /$ $\mathrm{m}^{3}$ 로부터 $9.56 \mu \mathrm{g} / \mathrm{m}^{3}$ 로 뚜렷하게 감소하는 것을 확
인할 수 있었다. 반면 ketone 그룹의 경우 E-0부터 E6 까지 $595 \mu \mathrm{g} / \mathrm{m}^{3}$ 로부터 $398 \mu \mathrm{g} / \mathrm{m}^{3}$ 로 소폭의 농도 감 소를 보이다가 E-9에 $1331 \mu \mathrm{g} / \mathrm{m}^{3}$ 를 나타내며 E-6에 비해 약 3 배 증가하였다. 이외의 다른 그룹들의 경우 농도변화에 있어서 눈에 띄는 큰 변화는 없었으며 증 가와 감소를 반복 하였다.

Table 3에는 시간의 경과에 따른 $\mathrm{VOC}$ 의 발생물질 을 발생성분의 빈도(개수)로 나누어 비교한 결과, alcohol 그룹의 $\mathrm{VOC}$ 들이 52 개로 가장 많이 발생하였 다. 반면 ester 그룹의 경우, 전체기간 동안 8 개로 가 장 적게 발생하는 것을 확인하였다. Sulfur 그룹과 ketone 그룹의 경우 20 개와 23 개로 발생농도의 비중 이 상대적으로 높게 나타났다. Table 3에서 각 조사시 점에서의 발생 성분을 표기한 개수 정보 옆의 괄호 안은 바로 직전 시점에 분석한 샘플과 동일하게 발생 한 화합물질의 개수를 의미한다. 총 개수(Total) 옆에 표기한 괄호는 분석기간 동안 발생한 개별 물질들의 반복 횟수를 제외한 실제 화합물의 종류를 의미한다. 위의 결과를 살펴 본 결과 몇 개의 특정물질들은 $\mathrm{VOC}$ 의 발생 개수보다 냄새에 대한 영향이 더 크다는 것을 확인할 수 있었다(Fig. 2).

Table 3. Total concentration and occurrence frequency of odorants released from Spam samples

\begin{tabular}{|c|c|c|c|c|c|c|}
\hline \multirow{2}{*}{ Groups } & \multicolumn{6}{|c|}{ Sample code } \\
\hline & E-0 & E-1 & E-3 & E-6 & E-9 & Total \\
\hline & \multicolumn{6}{|c|}{ Total concentration $\left(\ddot{I} g / \mathrm{m}^{3}\right)$} \\
\hline A. Sulfur & 1613 & 509 & 138 & 22.5 & 9.56 & 2292 \\
\hline B. Alcohol & 89.8 & 124 & 131 & 41.3 & 76.2 & 463 \\
\hline C. Aldehyde & 41.6 & 105 & 74.5 & 23.0 & 29.7 & 273 \\
\hline D. Ketone & 595 & 585 & 523 & 398 & 1331 & 3431 \\
\hline E. Ester & 8.74 & 8.90 & 11.9 & 5.39 & 1.01 & 36.0 \\
\hline F. Aromatics & 2.43 & 9.56 & 5.31 & 0.23 & 1.71 & 19.2 \\
\hline G. Acid & 13.0 & 133 & 69.0 & 34.2 & 116 & 365 \\
\hline H. Miscellaneous & 79.3 & 155 & 92.3 & 51.2 & 72.3 & 450 \\
\hline \multirow[t]{2}{*}{ Total } & 2442 & 1629 & 1045 & 575 & 1637 & 7329 \\
\hline & \multicolumn{6}{|c|}{ Frequency } \\
\hline A. Sulfur & 5 & $5(5)^{a)}$ & $4(4)$ & $3(3)$ & $3(3)$ & $20(5)^{b)}$ \\
\hline B. Alcohol & 8 & $9(8)$ & $11(9)$ & $13(11)$ & $11(10)$ & $52(14)$ \\
\hline C. Aldehyde & 8 & $7(7)$ & $7(7)$ & $7(7)$ & $6(5)$ & $35(8)$ \\
\hline D. Ketone & 4 & $4(4)$ & $5(4)$ & $5(5)$ & $5(4)$ & $23(6)$ \\
\hline E. Ester & 1 & $1(1)$ & $1(1)$ & $3(1)$ & $2(1)$ & $8(4)$ \\
\hline F. Aromatics & 5 & $4(4)$ & $4(4)$ & $3(3)$ & $4(3)$ & $20(5)$ \\
\hline G. Acid & 3 & $1(1)$ & $2(1)$ & $3(2)$ & $2(1)$ & $11(5)$ \\
\hline H. Miscellaneous & 13 & $14(8)$ & $18(11)$ & $11(8)$ & $16(9)$ & $13(32)$ \\
\hline
\end{tabular}

a) Numbers in parentheses denote the number of newly detected compounds compared with previous samples

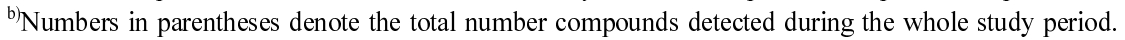




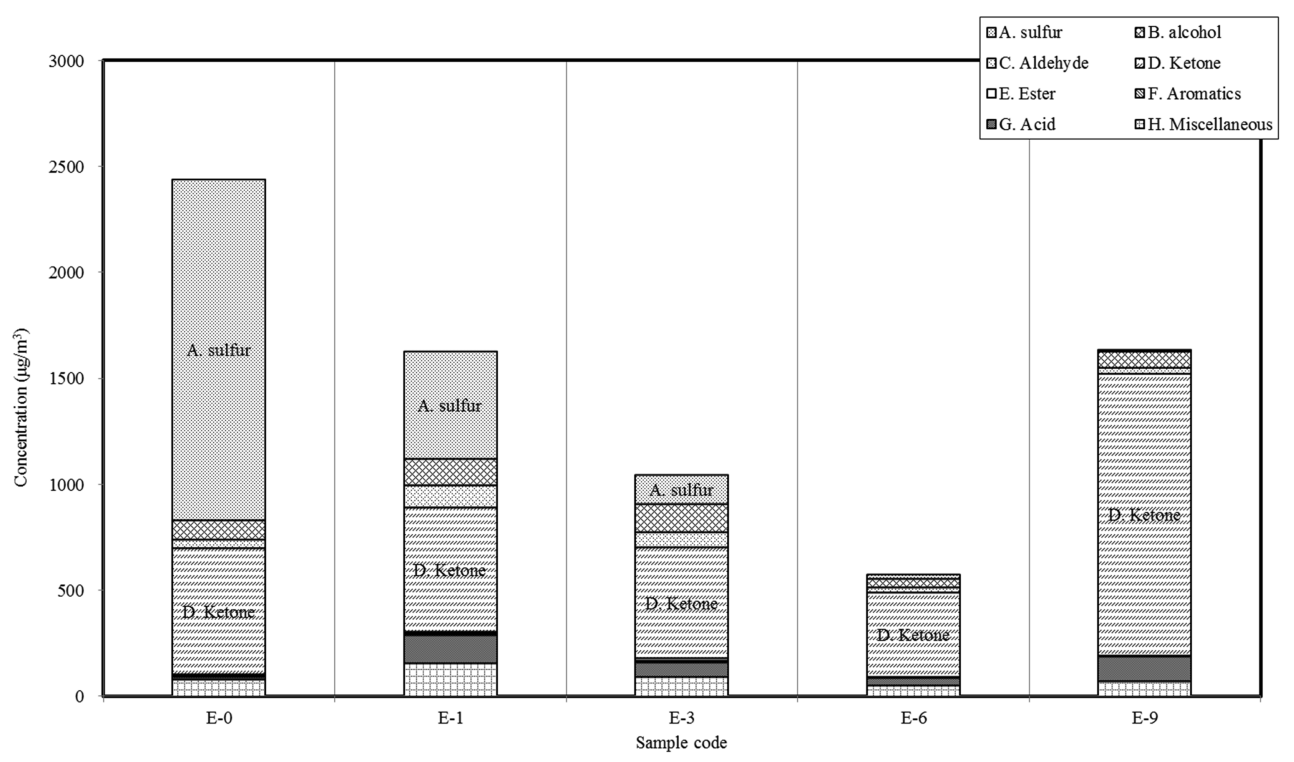

A. Concentration

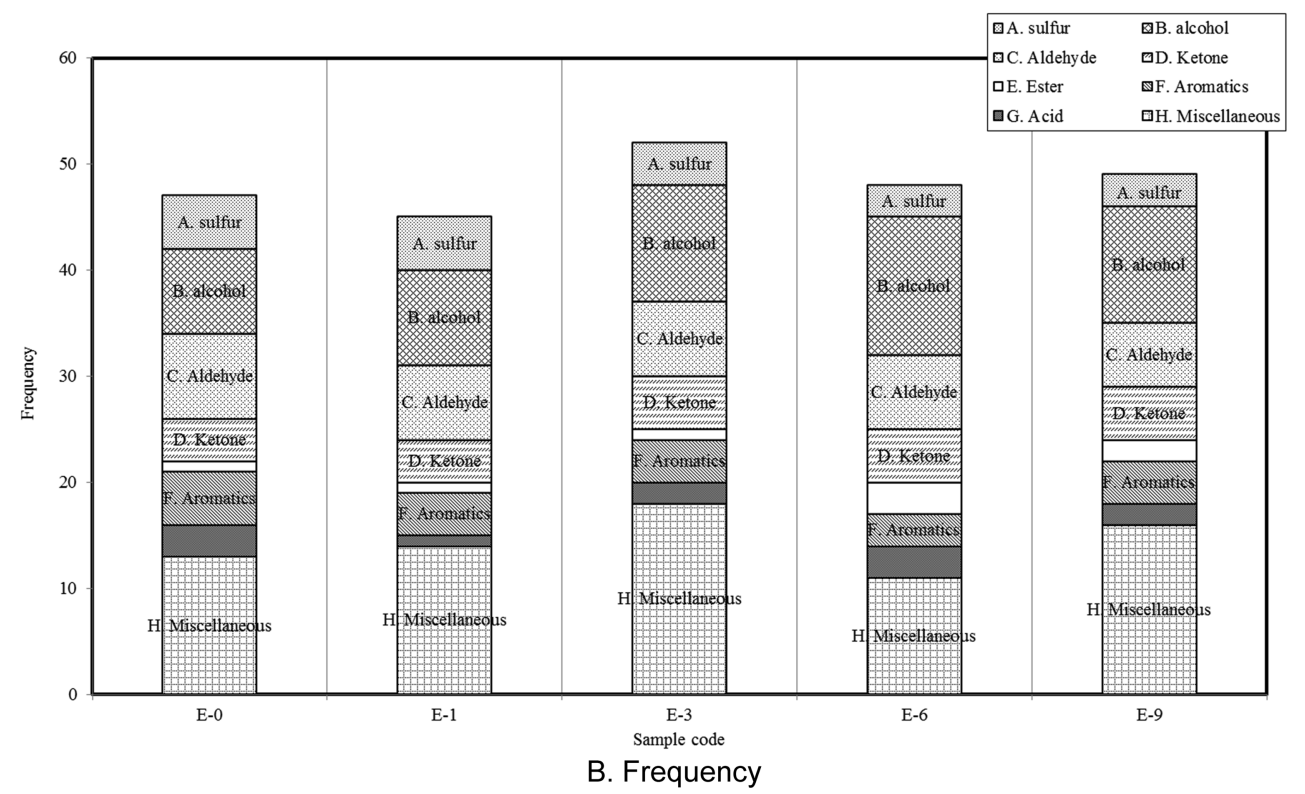

Fig. 2. Concentration and occurrence frequency of VOC and sulfur gases emitted from Spam samples through time.

\section{3. 시간의 경과에 따른 발생농도의 분포}

Table 4에 제시한 바와 같이 스팸에서 발생하는 $\mathrm{VOC}$ 와 황화합물들을 $\mathrm{GC} / \mathrm{MS}$ 와 $\mathrm{GC} / \mathrm{PFPD}$ 시스템을 이용하여 분석한 결과, 검출한계 이상의 성분은 총 80 종으로 나타났다. 개별 성분들의 농도에 상응하는 악 취의 세기를 파악하기 위하여, 분석 일자별로 측정한 개별성분의 농도를 Table 4에 제시한 전체 농도의 합 을 이용한 퍼센트 $(\%)$ 단위의 분율로도 제시하였다
(이때, 기기검출한계 이하의 결과값은 제외하였다). 분 석 기간 동안 전체농도 대비 $1 \%$ 이상을 차지하는 성 분은 48 개로 나타났다. 그 중 $1 / 4$ 에 해당하는 ketone 그룹에서 12 개의 성분들이 발생 빈도 및 비중에서 모 두 높게 나타났다. Sulfur 그룹의 경우 발생성분의 농 도 및 비중 값이 $\mathrm{E}-0$ 에서는 $1613 \mu \mathrm{g} / \mathrm{m}^{3}(66.0 \%)$ 인데 반해, E-1은 $509 \mu \mathrm{g} / \mathrm{m}^{3}(31.3 \%)$ 으로 $\mathrm{E}-0$ 에 비해 절반 가까이 줄어들었다. 시료 채취 마지막 날인 E-9에서는 
Table 4. Comparison of mass per volume concentration and the corresponding relative composition (RC) of odorants emitted from Spam samples

\begin{tabular}{|c|c|c|c|c|c|c|c|c|c|c|c|}
\hline \multirow{2}{*}{ Order } & \multirow{2}{*}{ Compounds } & \multicolumn{5}{|c|}{ Concentration $\left(\mu \mathrm{g} / \mathrm{m}^{3}\right)$} & \multicolumn{5}{|c|}{$\mathrm{RC}(\%)^{\mathrm{a}}$} \\
\hline & & E-0 & E-1 & E-3 & E-6 & E-9 & E-0 & E-1 & E-3 & E-6 & E-9 \\
\hline \multicolumn{12}{|c|}{ A. sulfur } \\
\hline 1 & Hydrogen sulfide & 1465 & 455 & 118 & 8.49 & 0.93 & 60.0 & 28.0 & 11.3 & 1.48 & 0.06 \\
\hline 2 & Methyl mercaptan & 131 & 33.1 & 10.2 & 1.97 & 2.18 & 5.35 & 2.03 & 0.97 & 0.34 & 0.13 \\
\hline 3 & Dimethyl sulfide & 7.13 & 5.48 & 1.42 & 0.04 & 0.04 & 0.29 & 0.34 & 0.14 & & \\
\hline 4 & Carbon disulfide & 9.13 & 14.6 & 8.54 & 11.9 & 6.39 & 0.37 & 0.90 & 0.82 & 2.07 & 0.39 \\
\hline 5 & Dimethyl disulfide & 1.16 & 0.65 & 0.03 & 0.03 & 0.03 & 0.05 & 0.04 & & & \\
\hline \multicolumn{12}{|c|}{ B. alcohol } \\
\hline 1 & 4-Pentyn-1-ol & 0.00 & 0.00 & 0.00 & 0.05 & 0.00 & & & & 0.01 & \\
\hline 2 & 2-Propanol & 18.6 & 23.8 & 22.4 & 10.63 & 45.5 & 0.76 & 1.46 & 2.15 & 1.85 & 2.78 \\
\hline 3 & sec-Butanol & 1.37 & 1.34 & 1.38 & 1.08 & 0.00 & 0.06 & 0.08 & 0.13 & 0.19 & 0.00 \\
\hline 4 & Dimethylvinylcarbinol & 1.13 & 1.62 & 1.80 & 0.92 & 0.71 & 0.05 & 0.10 & 0.17 & 0.16 & 0.04 \\
\hline 5 & iso-Butanol & 4.93 & 5.70 & 5.98 & 2.72 & 8.72 & 0.20 & 0.35 & 0.57 & 0.47 & 0.53 \\
\hline 6 & n-Butanol & 62.5 & 87.0 & 90.0 & 8.32 & 0.18 & 2.56 & 5.34 & 8.61 & 1.45 & 0.01 \\
\hline 7 & Ethyl vinyl carbinol & 0.00 & 0.00 & 0.00 & 0.00 & 0.29 & & & & & 0.02 \\
\hline 8 & Isopentyl alcohol & 0.00 & 0.00 & 0.00 & 0.73 & 15.6 & & & & 0.13 & 0.95 \\
\hline 9 & 1-Pentanol & 0.44 & 1.03 & 1.25 & 0.44 & 1.03 & 0.02 & 0.06 & 0.12 & 0.08 & 0.06 \\
\hline 10 & Isobutenylcarbinol & 0.63 & 1.56 & 1.62 & 1.46 & 2.31 & 0.03 & 0.10 & 0.15 & 0.25 & 0.14 \\
\hline 11 & Acetone alcohol & 0.00 & 0.00 & 4.12 & 13.2 & 0.00 & & & 0.39 & 2.30 & \\
\hline 12 & 1-Octen-3-ol & 0.00 & 0.00 & 0.18 & 0.28 & 0.47 & & & 0.02 & 0.05 & 0.03 \\
\hline 13 & 2-Ethyl-1-hexanol & 0.28 & 0.95 & 0.63 & 0.33 & 1.37 & 0.01 & 0.06 & 0.06 & 0.06 & 0.08 \\
\hline 14 & Furfuralcohol & 0.00 & 1.37 & 1.53 & 1.06 & 0.00 & & 0.08 & 0.15 & 0.18 & 0.00 \\
\hline \multicolumn{12}{|c|}{ C. Aldehyde } \\
\hline 1 & iso-Butylaldehyde & 6.55 & 24.7 & 20.7 & 2.82 & 1.60 & 0.27 & 1.52 & 1.98 & 0.49 & 0.10 \\
\hline 2 & Butylaldehyde & 1.20 & 2.27 & 1.77 & 0.17 & 0.00 & 0.05 & 0.14 & 0.17 & 0.03 & \\
\hline 3 & 2-Methylbutyraldehyde & 7.70 & 17.6 & 9.68 & 1.58 & 1.83 & 0.32 & 1.08 & 0.93 & 0.27 & 0.11 \\
\hline 4 & iso-Valeraldehyde & 13.9 & 37.4 & 25.0 & 16.0 & 23.9 & 0.57 & 2.29 & 2.39 & 2.78 & 1.46 \\
\hline 5 & n-Valeraldehyde & 7.42 & 14.8 & 10.3 & 0.41 & 0.00 & 0.30 & 0.91 & 0.99 & 0.07 & \\
\hline 6 & Hexanal & 2.03 & 6.77 & 5.76 & 1.08 & 0.92 & 0.08 & 0.42 & 0.55 & 0.19 & 0.06 \\
\hline 7 & Nonyl aldehyde & 0.85 & 0.00 & 0.00 & 0.00 & 0.65 & 0.03 & & & & 0.04 \\
\hline 8 & Benzaldehyde & 1.89 & 1.13 & 1.27 & 0.92 & 0.78 & 0.08 & 0.07 & 0.12 & 0.16 & 0.05 \\
\hline \multicolumn{12}{|c|}{ D. Ketone } \\
\hline 1 & Acetone & 541 & 520 & 451 & 369 & 1150 & 22.1 & 31.9 & 43.2 & 64.2 & 70.2 \\
\hline 2 & Methyl ethyl ketone & 44.0 & 55.2 & 53.0 & 11.8 & 1.27 & 1.80 & 3.39 & 5.07 & 2.05 & 0.08 \\
\hline 3 & Methyl propyl ketone & 0.00 & 0.00 & 0.00 & 0.00 & 0.61 & & & & & 0.04 \\
\hline 4 & 2,3-Butanedione & 9.95 & 9.60 & 17.5 & 16.1 & 179 & 0.41 & 0.59 & 1.68 & 2.80 & 10.9 \\
\hline 5 & Methyl isobutyl ketone & 0.18 & 0.11 & 0.17 & 0.10 & 0.05 & 0.01 & 0.01 & 0.02 & 0.02 & 0.00 \\
\hline 6 & 2,3-Pentanedione & 0.00 & 0.00 & 0.61 & 0.25 & 0.00 & & & 0.06 & 0.04 & \\
\hline \multicolumn{12}{|c|}{ E. Ester } \\
\hline 1 & $\begin{array}{l}\text { 1,2,4-Benzenetricarboxylic } \\
\text { acid, 1,2-dimethyl ester }\end{array}$ & 0.00 & 0.00 & 0.00 & 0.20 & 0.00 & & & & 0.03 & \\
\hline 2 & tert-butylmethyl ether & 0.00 & 0.00 & 0.00 & 0.00 & 0.47 & & & & & 0.03 \\
\hline 3 & Ethylene glycol monobutyl ether & 8.74 & 8.90 & 11.9 & 5.13 & 0.54 & 0.36 & 0.55 & 1.14 & 0.89 & 0.03 \\
\hline 4 & Methyl tetrahydrofurfuryl ether & 0.00 & 0.00 & 0.00 & 0.07 & 0.00 & & & & 0.01 & \\
\hline
\end{tabular}

$9.56 \mu \mathrm{g} / \mathrm{m}^{3}(0.58 \%)$ 로 급격히 떨어지는 것을 확인하였 다. 그 중 E-0에서 가장 높은 농도로 나타났던 hydrogen sulfide의 경우, E-0에 비해 E-9에서는 약 1500 배가
떨어진 $0.93 \mu \mathrm{g} / \mathrm{m}^{3}(0.06 \%)$ 로 나타났다. 반면, ketone 그룹의 경우 발생성분의 농도 및 비중이 E- 0 의 경우 $595 \mu \mathrm{g} / \mathrm{m}^{3}(24.4 \%)$ 에서 $\mathrm{E}-9$ 의 $1331 \mu \mathrm{g} / \mathrm{m}^{3}(81.3 \%)$ 로 
Table 4. Continued

\begin{tabular}{|c|c|c|c|c|c|c|c|c|c|c|c|}
\hline \multirow{2}{*}{ Order } & \multirow{2}{*}{ Compounds } & \multicolumn{5}{|c|}{ Concentration $\left(\mu \mathrm{g} / \mathrm{m}^{3}\right)$} & \multicolumn{5}{|c|}{$\mathrm{RC}(\%)^{\mathrm{a}}$} \\
\hline & & E-0 & E-1 & E-3 & E-6 & E-9 & E-0 & E-1 & $\mathrm{E}-3$ & E-6 & E-9 \\
\hline \multicolumn{12}{|c|}{ F. Aromat ics } \\
\hline 1 & Ethylbenzene & 0.17 & 0.38 & 0.26 & 0.13 & 0.21 & 0.01 & 0.02 & 0.02 & 0.02 & 0.01 \\
\hline 2 & p-Xylene & 0.09 & 0.14 & 0.12 & 0.03 & 0.09 & 0.00 & 0.01 & 0.01 & 0.00 & 0.01 \\
\hline 3 & m-Xylene & 0.22 & 0.33 & 0.23 & 0.08 & 0.18 & 0.01 & 0.02 & 0.02 & 0.01 & 0.01 \\
\hline 4 & Styrene & 0.29 & 0.00 & 0.00 & 0.00 & 0.00 & 0.01 & 0.00 & & & \\
\hline 5 & Toluene & 1.65 & 8.70 & 4.71 & 0.00 & 1.22 & 0.07 & 0.53 & 0.45 & & 0.07 \\
\hline \multicolumn{12}{|c|}{ G. Acid } \\
\hline 1 & $\begin{array}{l}\text { 4-Terpinenyl ester of n-butanoic } \\
\text { acid }\end{array}$ & 0.00 & 0.00 & 0.00 & 0.00 & 0.08 & & & & & 0.01 \\
\hline 2 & Aceticd acid & 11.9 & 133 & 68.6 & 33.3 & 116 & 0.49 & 8.14 & 6.56 & 5.78 & 7.08 \\
\hline 3 & n-Butyric acid & 0.87 & 0.00 & 0.00 & 0.77 & 0.00 & 0.04 & & & 0.13 & \\
\hline 4 & n-Valeric acid & 0.24 & 0.00 & 0.00 & 0.00 & 0.00 & 0.01 & & & 0.00 & \\
\hline 5 & iso-Valeric acid & 0.00 & 0.00 & 0.39 & 0.14 & 0.00 & & & 0.04 & 0.03 & \\
\hline \multicolumn{12}{|c|}{ H. Miscellaneous } \\
\hline 1 & n-Hexane & 1.31 & 0.68 & 1.32 & 0.45 & 0.56 & 0.05 & 0.04 & 0.13 & 0.08 & 0.03 \\
\hline 2 & 1,1-Dichloro-1-fluoroethane & 9.17 & 9.33 & 3.40 & 0.00 & 0.00 & 0.38 & 0.57 & 0.33 & & \\
\hline 3 & 1,3-Cyclopentadiene & 0.49 & 0.73 & 0.22 & 0.00 & 0.00 & 0.02 & 0.04 & 0.02 & & \\
\hline 4 & 1-Heptene & 0.00 & 0.00 & 0.00 & 0.00 & 0.07 & & & & & 0.00 \\
\hline 5 & 2,4-Dimethylhexane & 0.00 & 0.50 & 0.51 & 0.00 & 0.00 & & 0.03 & 0.05 & & \\
\hline 6 & n-Octane & 0.00 & 0.00 & 0.00 & 0.00 & 0.65 & & & & & 0.04 \\
\hline 7 & 2,3,4-Trimethylhexane & 0.35 & 0.00 & 0.00 & 0.11 & 0.00 & 0.01 & & & 0.02 & \\
\hline 8 & Tetrahydrofuran & 0.00 & 0.00 & 0.98 & 0.42 & 0.69 & 0.09 & & & 0.07 & 0.04 \\
\hline 9 & 2-Methylfuran & 3.84 & 4.54 & 2.08 & 0.49 & 0.39 & 0.16 & 0.28 & 0.20 & 0.09 & 0.02 \\
\hline 10 & 2-Methylfuran & 0.54 & 1.09 & 0.66 & 0.24 & 0.00 & 0.02 & 0.07 & 0.06 & 0.04 & \\
\hline 11 & Trimethylsilyl-di(timethylsiloxy)-silane & 0.00 & 2.55 & 0.00 & 0.00 & 0.00 & & 0.16 & & & \\
\hline 12 & $\begin{array}{l}\text { Cobalt, (2-methyl-.eta.-3-propenyl) } \\
\text {-(pentamethylcyclopentadienyl)- }\end{array}$ & 0.12 & 0.00 & 0.00 & 0.00 & 0.00 & 0.005 & & & & \\
\hline 13 & Acetonitrile & 0.00 & 14.4 & 11.2 & 0.00 & 0.00 & & 0.88 & 1.07 & & \\
\hline 14 & Methyl isocyanide & 11.8 & 0.00 & 0.00 & 5.25 & 3.26 & 0.48 & & & 0.91 & 0.20 \\
\hline 15 & $\alpha$-Pinene & 0.18 & 0.33 & 0.24 & 0.13 & 0.14 & 0.01 & 0.02 & 0.02 & 0.02 & 0.01 \\
\hline 16 & Chloroform & 48.3 & 95.4 & 67.5 & 41.9 & 63.4 & 1.98 & 5.86 & 6.46 & 7.28 & 3.87 \\
\hline 17 & 1,1-Dimethoxybutane & 0.00 & 0.00 & 0.00 & 0.00 & 0.35 & 0.00 & 0.00 & 0.00 & 0.00 & 0.02 \\
\hline 18 & 3-Methylthiophene & 0.61 & 1.05 & 0.75 & 0.52 & 0.58 & 0.03 & 0.06 & 0.07 & 0.09 & 0.04 \\
\hline 19 & $\begin{array}{l}\text { Bicyclo[3.1.1]heptane, 6,6-dimethyl-2- } \\
\text { methylene-, (1S)- }\end{array}$ & 0.00 & 0.00 & 0.20 & 0.00 & 0.00 & & & 0.02 & & \\
\hline 20 & 1,3-Dioxolane & 0.00 & 22.9 & 0.00 & 0.00 & 0.00 & & 1.41 & & & \\
\hline 21 & 3,7-Dimethylnonane & 0.00 & 0.00 & 0.00 & 0.00 & 0.07 & & & & & 0.00 \\
\hline 22 & Limonene & 0.00 & 0.00 & 0.15 & 0.00 & 0.00 & & & 0.01 & & \\
\hline 23 & 2-Pcntylfuran & 0.00 & 0.00 & 0.00 & 0.00 & 0.07 & & & & & 0.00 \\
\hline 24 & Pyrazine & 1.86 & 0.00 & 0.00 & 0.00 & 0.00 & 0.08 & & & & \\
\hline 25 & Cyclooctatetraene & 0.00 & 0.07 & 0.00 & 0.00 & 0.00 & & 0.00 & & & \\
\hline 26 & Methylpyrazine & 0.82 & 0.00 & 1.15 & 1.51 & 1.27 & 0.03 & & 0.11 & 0.26 & 0.08 \\
\hline 27 & $\begin{array}{l}\text { 5,9-Dodecadien-2-one, 6,10-dimethyl-, } \\
(\mathrm{E}, \mathrm{E}) \text { )- }\end{array}$ & 0.00 & 0.00 & 0.50 & 0.00 & 0.00 & & & 0.05 & & \\
\hline 28 & 1,2-Dichlorobenzene & 0.00 & 0.00 & 0.24 & 0.00 & 0.43 & & & 0.02 & & 0.03 \\
\hline 29 & Tetramethylbutanedinitrile & 0.00 & 1.11 & 1.12 & 0.00 & 0.00 & & 0.07 & 0.11 & & 0.00 \\
\hline 30 & Propanenitrile, 2,2'-azobis[2-methyl- & 0.00 & 0.00 & 0.00 & 0.21 & 0.19 & & & & 0.04 & 0.01 \\
\hline 31 & $\begin{array}{l}\text { N-[1-(4-Hydroxy-5-hydroxymeth- } \\
\text { yltetrahydrofuran-2-yl)-4-oxo-1,4- } \\
\text { dihydropyrimidin-2-yl]benzamide }\end{array}$ & 0.00 & 0.00 & 0.00 & 0.00 & 0.15 & & & & & 0.01 \\
\hline 32 & 2-Ethyl-1-hexanol & 0.00 & 0.00 & 0.08 & 0.00 & 0.00 & & & 0.01 & & \\
\hline
\end{tabular}

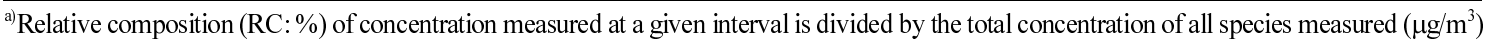


Table 5. Odor activity value (OAV) and the corresponding relative proportion (RP) of odorants emitted from Spam samples

\begin{tabular}{|c|c|c|c|c|c|c|c|c|c|c|c|c|}
\hline \multirow{2}{*}{ Orde } & \multirow{2}{*}{ Compounds } & \multirow{2}{*}{$\begin{array}{c}\text { Threshold } \\
\text { (ppbv) }\end{array}$} & \multicolumn{5}{|c|}{ OAV (concentration/Threshold [ppbv/ppbv]) ${ }^{\mathrm{a}}$} & \multicolumn{5}{|c|}{$\mathrm{RP}(\%)^{\mathrm{b})}$} \\
\hline & & & E-0 & E-1 & E-3 & E-6 & E-9 & E-0 & E-1 & E-3 & E-6 & E-9 \\
\hline \multicolumn{13}{|c|}{ A. sulfur } \\
\hline 1 & Hydrogen sulfide & 17.8 & 19.4 & 6.02 & 1.56 & 0.11 & 0.01 & 78.3 & 41.7 & 19.8 & 3.19 & 0.08 \\
\hline 2 & Methyl mercaptan & 41.8 & 1.59 & 0.40 & 0.12 & 0.02 & 0.03 & 6.44 & 2.80 & 1.57 & 0.68 & 0.17 \\
\hline 3 & Dimethyl sulfide & 20.0 & 0.14 & 0.11 & 0.03 & & & 0.57 & 0.75 & 0.35 & & \\
\hline 4 & Carbon disulfide & 7,436 & 0.00 & 0.00 & 0.00 & 0.00 & 0.00 & 0.00 & 0.00 & 0.00 & 0.01 & 0.00 \\
\hline 5 & Dimethyl disulfide & 90.2 & 0.00 & 0.00 & & & & 0.01 & 0.01 & & & \\
\hline \multicolumn{13}{|c|}{ B. alcohol } \\
\hline 1 & 2-Propanol & 199,800 & 0.00 & 0.00 & 0.00 & 0.00 & 0.00 & 0.00 & 0.00 & 0.00 & 0.00 & 0.00 \\
\hline 2 & sec-Butanol & 1,700 & 0.00 & 0.00 & 0.00 & 0.00 & & 0.00 & 0.00 & 0.00 & 0.01 & \\
\hline 3 & iso-Butanol & 832 & 0.00 & 0.00 & 0.00 & 0.00 & 0.00 & 0.01 & 0.02 & 0.03 & 0.03 & 0.02 \\
\hline 4 & n-Butanol & 26,000 & 0.00 & 0.00 & 0.00 & 0.00 & 0.00 & 0.00 & 0.01 & 0.01 & 0.00 & 0.00 \\
\hline 5 & Isopentyl alcohol & 44.7 & & & & 0.00 & 0.10 & & & & 0.13 & 0.63 \\
\hline 6 & 1-Pentanol & 468 & 0.00 & 0.00 & 0.00 & 0.00 & 0.00 & 0.00 & 0.00 & 0.01 & 0.01 & 0.00 \\
\hline 7 & 1-Octen-3-ol & 2.26 & & & 0.01 & 0.02 & 0.04 & & & 0.19 & 0.68 & 0.26 \\
\hline 8 & 2-Ethyl-1-hexanol & 246 & 0.00 & 0.00 & 0.00 & 0.00 & 0.00 & 0.00 & 0.01 & 0.01 & 0.01 & 0.01 \\
\hline 9 & Furfuralcohol & 7,989 & & & 0.00 & 0.00 & 0.00 & & 0.00 & 0.00 & 0.00 & \\
\hline \multicolumn{13}{|c|}{ C. Aldehyde } \\
\hline 1 & iso-Butylaldehyde & 40.7 & 0.05 & 0.21 & 0.17 & 0.02 & 0.01 & 0.22 & 1.43 & 2.19 & 0.67 & 0.09 \\
\hline 2 & Butylaldehyde & 9,022 & 0.00 & 0.00 & 0.00 & 0.00 & & 0.00 & 0.00 & 0.00 & 0.00 & \\
\hline 3 & iso-Valeraldehyde & 2.24 & 1.77 & 4.75 & 3.17 & 2.03 & 3.04 & 7.16 & 32.9 & 40.3 & 57.7 & 19.9 \\
\hline 4 & n-V aleraldehyde & 2.30 & 0.92 & 1.83 & 1.28 & 0.05 & & 3.71 & 12.6 & 16.2 & 1.45 & \\
\hline 5 & Hexanal & 13.8 & 0.04 & 0.12 & 0.10 & 0.02 & 0.02 & 0.15 & 0.83 & 1.30 & 0.55 & 0.11 \\
\hline 6 & Nonyl aldehyde & 2.24 & 0.07 & & & & 0.05 & 0.26 & & & & 0.32 \\
\hline 7 & Benzaldehyde & 42.1 & 0.01 & 0.01 & 0.01 & 0.01 & 0.00 & 0.04 & 0.04 & 0.09 & 0.14 & 0.03 \\
\hline \multicolumn{13}{|c|}{ D. Ketone } \\
\hline 1 & Acetone & 680,751 & 0.00 & 0.00 & 0.00 & 0.00 & 0.00 & 0.00 & 0.00 & 0.00 & 0.01 & 0.00 \\
\hline 2 & Methyl ethyl ketone & 50,120 & 0.00 & 0.00 & 0.00 & 0.00 & 0.00 & 0.00 & 0.00 & 0.00 & 0.00 & 0.00 \\
\hline 3 & Methyl propyl ketone & 1,550 & & & & & 0.00 & & & & & 0.00 \\
\hline 4 & 2,3-Butanedione & 4.37 & 0.65 & 0.62 & 1.14 & 1.05 & 11.6 & 2.62 & 4.32 & 14.5 & 29.8 & 76.2 \\
\hline 5 & Methyl isobutyl ketone & 47,145 & 0.00 & 0.00 & 0.00 & 0.00 & 0.00 & 0.00 & 0.00 & 0.00 & 0.00 & 0.00 \\
\hline 6 & 2,3-Pentanedione & 5.13 & & & 0.03 & 0.01 & & & & 0.37 & 0.34 & \\
\hline \multicolumn{13}{|c|}{ F. Aromatics } \\
\hline 1 & Ethylbenzene & 170 & 0.00 & 0.00 & 0.00 & 0.00 & 0.00 & 0.00 & 0.00 & 0.00 & 0.00 & 0.00 \\
\hline 2 & p-Xylene & 490 & 0.00 & 0.00 & 0.00 & 0.00 & 0.00 & 0.00 & 0.00 & 0.00 & 0.00 & 0.00 \\
\hline 3 & m-Xylene & 41.0 & 0.00 & 0.00 & 0.00 & 0.00 & 0.00 & 0.01 & 0.01 & 0.02 & 0.01 & 0.01 \\
\hline 4 & Styrene & 35.0 & 0.00 & & & & & 0.01 & & & & \\
\hline 5 & Toluene & 39,889 & 0.00 & 0.00 & 0.00 & & 0.00 & 0.00 & 0.00 & 0.00 & & 0.00 \\
\hline \multicolumn{13}{|c|}{ G. Acid } \\
\hline 1 & Aceticd acid & 145 & 0.03 & 0.37 & 0.19 & 0.09 & 0.33 & 0.13 & 2.58 & 2.45 & 2.66 & 2.13 \\
\hline 2 & n-Butyric acid & 3.89 & 0.06 & & & 0.06 & & 0.25 & & & 1.57 & \\
\hline 3 & n-Valeric acid & 4.79 & 0.01 & & & & & 0.05 & & & & \\
\hline 4 & iso-Valeric acid & 2.46 & & & 0.04 & 0.01 & & & & 0.48 & 0.40 & \\
\hline \multicolumn{13}{|c|}{ H. Miscellaneous } \\
\hline 1 & n-H exane & 21,900 & 0.00 & 0.00 & 0.00 & 0.00 & 0.00 & 0.00 & 0.00 & 0.00 & 0.00 & 0.00 \\
\hline 2 & 1,3-Cyclopentadiene & 1,878 & 0.00 & 0.00 & 0.00 & & & 0.00 & 0.00 & 0.00 & & \\
\hline 3 & 2-Methylfuran & 259,317 & & & & & 0.00 & & & & & 0.00 \\
\hline 4 & $\mathrm{n}-\mathrm{O}$ ctane & 24,678 & 0.00 & 0.00 & 0.00 & 0.00 & 0.00 & 0.00 & 0.00 & 0.00 & 0.00 & 0.00 \\
\hline 5 & Acetonitrile & 97,700 & & 0.00 & 0.00 & & & & 0.00 & 0.00 & & \\
\hline 6 & $\alpha-P$ inene & 18.0 & 0.00 & 0.00 & 0.00 & 0.00 & 0.00 & 0.01 & 0.02 & 0.03 & 0.04 & 0.01 \\
\hline 7 & Chloroform & 207,333 & 0.00 & 0.00 & 0.00 & 0.00 & 0.00 & 0.00 & 0.00 & 0.00 & 0.00 & 0.00 \\
\hline 8 & Limonene & 38.0 & & & 0.00 & & & & & 0.01 & & \\
\hline 9 & 2-Pcntylfuran & 15.9 & & & & & 0.00 & & & & & 0.01 \\
\hline
\end{tabular}

a) [Concentration (ppbv)/OT (ppbv)]

${ }^{\mathrm{b}}$ Relative proportion (RP: \%) of OAV at a given time divided by the total OAV of all species measured (ppbv) 
꾸준한 증가경향을 보였다. 그 중 acetone의 경우, 시 료채취 마지막 날인 E-9에서 $1150 \mu \mathrm{g} / \mathrm{m}^{3}(70.2 \%)$ 으로 E-0에 비해 발생농도가 약 3 배 증가하였다. ester그룹 과 aromatics 그룹에 속해있는 9 개 성분의 경우 시료 채취 전체 일정동안 ethylene glycol monobutyl ether 성분의 농도 및 비중이 E-3에서 $11.9 \mu \mathrm{g} / \mathrm{m}^{3}(1.14 \%)$ 로 가장 크게 나타났다. 나머지 성분들의 경우 발생 농도 및 비중이 차지하는 양은 $11.0 \mu \mathrm{g} / \mathrm{m}^{3}(0.88 \%)$ 이하를 나타냈다. 즉, ester그룹과 aromatics 그룹에 속해 있는 성분들의 경우 그 발생량이 아주 미미하다는 것을 확 인하였다. 결과적으로, 스팸에서 발생하는 냄새의 경 우 sulfur그룹과 ketone그룹의 성분들이 양적인 면에서 주를 이룬다는 것을 확인하였다.

\section{4. 스팸에서 발생하는 $\mathrm{VOC}$ 중 냄새 기여도의 정도 파악}

양적인 면에서 VOC와 sulfur는 스팸에서 발생하는 냄새의 상당부분을 차지하는 것으로 나타나 이들의 실질적인 악취기여도를 평가하였다. 개별성분에 따라 최소감지농도(odor threshold $(\mathrm{OT}))^{12-14}$ 의 차지를 감안 하여, 스팸에서 발생하는 개별성분들의 농도 값(ppbv) 을 최소감지농도 값(ppbv)으로 나누어 $\mathrm{OAV}$ (odor activity value)값을 산출 하였다. Table 5에 80 개의 전 체 성분 중 최소감지농도의 확인이 가능한 45 개 성 분들의 $\mathrm{OAV}$ 값을 도출하였다. 그리고 이를 이용하여 시료채취 일자별로 발생한 개별성분들의 $\mathrm{OAV}$ 에 대한 기여 비율을 퍼센트 $(\%)$ 값으로도 제시하였다. 발생성 분의 $\mathrm{OAV}$ 값이 1 보다 높은 경우, 주요냄새 성분으 로 추정할 수 있다.

이를 위해 스팸에서 발생하는 냄새를 그룹별로 구 분하여 주요냄새 성분을 추정하였다. 실험 전체 일정 중 sulfur, aldehyde, ketone, acid 그룹에서 몇 개의 성 분들의 $\mathrm{OAV}$ 가 1 보다 높게 나타났다. 반면, alcohol, aromatics 및 Miscellaneous 그룹에서는 모든 일정 및 모든 성분들에서 $\mathrm{OAV}$ 가 1 보다 낮아 악취발생의 기 여도가 낮은 것으로 나타났다. $\mathrm{OAV}$ 값이 1 보다 높 은 성분들에 국한하여 비교한 결과, E-0에 hydrogen sulfide의 OAV $1.94(78.3 \%)$, iso-valeraldeyde $1.77(7.2 \%)$ 의 순으로 최고를 기록하였다. E- 1 에서는 양성분들의 $\mathrm{OAV}$ 값 및 $\%$ 값의 차이가 각각 $6.02(41.7 \%), 4.75$ $(32.9 \%)$ 로 나타났다. E-3의 경우 hydrogen sulfide 1.56 (19.8\%)와 iso-valeraldeyde $3.17(40.3 \%)$ 으로 두 가지 발생성분의 농도 및 비중이 E-0과 반대의 성향을 보였 다. 또한 n-valeraldehyde와 2,3-butanedione성분이 각각
$1.28(16.2 \%), 1.14(14.5 \%)$ 로 E-3의 발생 냄새에 전반적 인 영향을 미쳤다. E-6의 경우, iso-valeraldeyde성분이 2.03 (57.7\%)발생하였고, 2,3-butanedione성분이 1.05 (29.8\%)로 그 뒤를 이었다. 분석 마지막 날인 E-9에서 는 2,3-butanedione성분에서 11.6(76.2\%)로 가장 높고, iso-valeraldeyde성분이 3.04 (19.9\%)로 그 뒤를 이었다. E-0에서 가장 높게 나타났던 hydrogen sulfide의 경우 $0.01(0.08 \%)$ 로 $\mathrm{OAV}$ 값 및 비중이 아주 미미한 것으로 나타났다. 즉, 앞서 신선기로 구분한 E-0, E-1에서는 hydrogen sulfide과 iso-valeraldeyde의 성분이 스팸에서 발생하는 성분 중 냄새에 가장 민감한 성분으로 판단 된다. 또한, 부패기로 구분한 E-3, E-6, E-9에서는 isovaleraldeyde와 2,3-butanedione성분이 가장 기여도가 큰 냄새 물질로 판단된다.

\section{4. 결 론}

본 연구에서는 염처리 음식물의 냄새성분 배출특성 을 파악하고자, 스팸을 이용하여 시간경과에 따른 발 생성분의 조성과 냄새의 기여도를 조사 하기 위해 실 험 기간을 신선기와 부패기로 구분하고, 각 시점에 발 생하는 냄새성분을 총 9 일 동안 5 회에 걸쳐 분석하 였다. 발생성분들의 농도뿐만 아니라 이들의 냄새 기 여도를 파악하기 위해, OAV값도 동시에 산출하여 비 교하였다. 분석 기간 동안 발생한 $\mathrm{VOC}$ 는 총 80 개로 나타났다. 신선기에 해당하는 E-0, E-1일에는 황화수소 의 농도가 각각 $1465 \mu \mathrm{g} / \mathrm{m}^{3}(60.0 \%), 455 \mu \mathrm{g} / \mathrm{m}^{3}(28.0 \%)$ 로 높게 나타났으며, $\mathrm{OAV}$ 값 또한 황화수소가 $19.4(78.3 \%), 6.02$ (41.7\%)로 신선기의 발생하는 냄새 를 좌우하는 주성분으로 나타났다. 부패기에 해당하는 E-3, E-6, E-9의 경우, ketone 그룹의 acetone의 농도가 각각 $451(43.2 \%), 369(64.2 \%), 1150 \mu \mathrm{g} / \mathrm{m}^{3}(70.2 \%)$ 로 나타났지만, $\mathrm{OAV}$ 는 $0.001(0.01 \%)$ 이하로 그 기여도가 미미하게 나타났다. OAV를 통해 부패기에서 발생하 는 냄새의 높은 비중을 차지하는 성분을 확인하여 본 결과, 또 다른 ketone류인 2,3-butanedione이 가장 큰 기여를 하였으며, 부패기 동안 발생한 2,3-butanedione 성분 농도는 $17.6 \mu \mathrm{g} / \mathrm{m}^{3}(1.68 \%), 16.1 \mu \mathrm{g} / \mathrm{m}^{3}(2.89 \%)$, $179 \mu \mathrm{g} / \mathrm{m}^{3}(10.9 \%)$ 로 acetone성분에 비해 농도는 낮지 만, $\mathrm{OAV}$ 값을 기준으로 $1.14(14.50 \%), 1.05(29.8 \%)$, $11.6(76.2 \%)$ 으로 나타났다.

본 연구결과, 시간 경과에 따라 신선기에는 sulfur 그룹에서 발생하는 성분이 지배적으로 나타났고, 신선 기와 부패기의 중간 시점에는 aldehyde 그룹의 영향을 
많이 받았다. 부패기에 접어들면서 ketone 그룹에서 발생하는 성분들이 스팸에서 발생하는 주요 냄새원인 으로 작용하는 것을 확인하였다.

\section{감사의 글}

본 연구는 한국연구재단의 지원을 통해 수행하였기 에 감사의 말씀을 전합니다(2009-0093848).

\section{참고문헌}

1. Korean Industrial Standards (KS) PRESSED HAM, KS H 3103200811 (2008. 11. 06).

2. Korea Meat Industries Association (KMIA) Meat products production and sales statistics (2011).

3. Korea Ministry of Environment (KMOE) Annual Report of Ambient Air Quality in Korea, (2007).

4. O. F. Hong and K. H. Kim, Kjore, 8(1), $12-19$ (2009)

5. H. J. Jo, O. F. Hong and K. H. Kim, Kosae (Journal of Korean Society for Atmospheric Environment), 27(2),
133-141 (2011a).

6. S. H. Jo, K. H. Kim, H. J. Jo, M. H. Lee, Y. H. Kim, J. H. Ahn, E. Y. Ryu and Y. W. Kim, Kjore, 11(2), 65-79 (2012b)

7. L. Cai, J. A. Koziel, Y. C. Lo and S. J. Hoff, J. Chromatogr. A, 1102, 60-72 (2006).

8. Y. C. M. Lo, W. S. Jenks, L. Cai, H. Xin and S. J. Hoff, JEQ, 37(2), 521-534 (2008).

9. S. Zhang, L. Cai, J. A. Koziel, S. J. Hoff, D. R. Schmidt, C. J. Clanton, L. D. Jacobson, D. B. Parkerd and A. J. Heber, Sens. Actuators B, 146(2), 427-432 (2010).

10. Y.-H. Kim and K.-H. Kim, J. Chromatogr. A (submitted).

11. Korea Ministry of Environment (KMOE) Malodor Prevention law of Korea Ministry of Environment (2008).

12. Y. Nagata and N. Takeuchi, JESC (Japan Environmental Sanitation Center), 17, 77-89 (1990).

13. J. H. Rurh, Am. Ind. Hyg. Assoc. J., 47, 142-151 (1986).

14. S. S. Schiffman, J. L. Bennett and J. H. Raymer, Agr Forest Meteorol, 108, 213-240 (2001). 